\title{
Noch ein Buch über Langlebigkeit
}

Das Pantheum Hygiasticum des Claudius Deodatus von 1628

Von Joseph Schürmann-Roth

In Gesnerus 42 (1985) 353-358 hat Marie-Louise Portmann ein Werk von Thomas Zwinger über Langlebigkeit vorgestellt. Die Zahl der in gleicher Absicht geschriebenen Bücher muß seinerzeit nicht gering gewesen sein. Schließlich war es ja das Ziel jedes Verfassers, der seinen Lesern gute Räte für die Gesundheit vermitteln wollte, damit auch deren Leben zu verlängern. 75 Jahre älter als Zwingers Buch ist ein ebenfalls auf heutigem Schweizer Boden entstandenes, gedrucktes und verlegtes Werk, das Pantheum Hygiasticum Hippocratico-Hermeticum de hominis vita ad centum et viginti annos salubriter producenda des Claudius Deodatus, gedruckt 1628 in Pruntrut bei Wilhelm Darbellay.

Über den Verfasser wissen unsere Lexika, Leu und Holzhalb sowie das Historisch-Biographische Lexikon nichts zu berichten. Ein Zusammenhang mit den aus Lucca stammenden Genfer Diodati ist angesichts des Unterschieds in den Konfessionen wenig wahrscheinlich. Nach Haller ${ }^{1}$ hat Claudius Deodatus 1605 «in Batavia» (also wohl in Leyden) eine Dissertation drucken lassen. Nach eigenen Angaben im Pantheum ${ }^{2}$ hat er drei Jahre danach im elsässischen Gebweiler praktiziert, und als er das Pantheum in Druck gab, war er «physicus ordinarius», also Leibarzt des Fürstbischofs von Basel. Er war auch einer der zahlreichen Korrespondenten des Fabricius Hildanus und hatte einen Sohn Johann Balthasar, der ebenfalls Arzt gewesen sein muß.

Das Titelblatt weist einen noch viel langatmigeren Text auf, als wir oben angegeben haben. Methusalem und Nestor kommen darin vor, und wenn sich Deodatus als «autor et collector» vorstellt, erweist sich bei näherem Zusehen, daß das Schwergewicht auf dem Sammeln liegt und weniger in kritischer Stellungnahme und im Mitteilen eigener Erfahrungen. Das Autorenverzeichnis von $3 \frac{1}{2}$ Seiten - nur die Namen der Verfasser sind wiedergegeben, nicht etwa die Titel ihrer Werke - enthält unter vielen andern Jakob Zwinger, den auch von Theodor Zwinger später benützten Cornaro 
und Hieronymus Guarinoni, den streitbaren, von gegenreformatorischen Ideen überquellenden Autor der damals wohl viel gelesenen «Grewel der Verwüstung menschlichen Geschlechts». Und erst noch fehlt in diesem Autorenverzeichnis jener Josephus Judaeus Allschweylensis, aus dessen Hausapotheke Deodatus einige Rezepte abschreibt ${ }^{3}$. - Wenn der Verfasser sein Werk unter das Motto der Verse 32-34 aus dem 37. Kapitel Ecclesiasticus (Jesus Sirach) stellt, so deutet er damit schon an, daß sich vernünftig und vorsichtig ernähren müsse, wer das in Aussicht gestellte Alter erreichen wolle.

Nachdem in einem über 400 Seiten umfassenden ersten Buch ausgiebig über «das Leben» und die verschiedenen Arten menschlicher Natur philosophiert worden ist, folgt eine Aufzählung der verschiedenen Nahrungsmittel, ihrer Qualitäten und ihres richtigen Gebrauchs. Schon da zeigt sich die Sammlerfunktion des Verfassers, der ganz gegensätzliche Auffassungen einander, ohne eigene Überzeugung hervorzuheben, gegenüberstellt. Ein zweites Buch von 212 Seiten bringt Anweisungen über Zubereitung und Einnahme der Speisen, über Ruhe und Schlaf, das Sexualleben ${ }^{4}$ mit Regeln, die von gegenreformatorischem Gedankengut geprägt sind. In einem dritten Buch von ungefähr gleichem Umfang wie das zweite wird an Medikamenten und äußerlichen Anwendungen alles aufgezählt, was sich in der Literatur sowohl der Hippokratiker wie der Spagyriker finden ließ bis zu Aderlaß, Blutegeln und dem Setzen von Fontanellen. Zu meiden empfiehlt Deodatus $^{5}$ : Aufregungen, Leidenschaften, Ehrgeiz, Geiz, Neid, Haß, Zorn ... kurzum, was wir heute unter «Streß im weitesten Sinn» zusammenfassen.

Sonst seien hier nur drei Einzelheiten erwähnt: Als Deodatus im Elsaß praktizierte, weigerte sich ein Bader, die vom Arzt angeordnete Phlebotomie an einem Schwerkranken auszuführen, weil «die Praktik», der Kalender, den Tag als ungünstig bezeichnete. Der Magistrat mußte einschreiten und befehlen, die Anweisung des Arztes sei auszuführen ... mit Erfolg für den Kranken. - Sogar den Säuglingen ersparte man das Fontanellensetzen nicht - wenigstens nach der Literatur -; ob es im Elsaß oder im Fürstbistum Basel wirklich jemals ausgeführt worden ist, bleibe dahingestellt. Ableitung böser Säfte im Genick hätte Tröckne des Hirns herbeiführen, vor Krämpfen bewahren, gegen jedes Rheuma widerstandsfähig und die Kinder später erst noch lernbegierig machen sollen. - Gegen die Pest werden vorab Prozessionen und Gebete empfohlen, dann aber auch Wachen an die Stadttore und schließlich ... Auswandern; auf die Pestbeulen hingegen sollen Laubfrösche aufgelegt werden, bis sie sterben. 
Die Rezeption der beiden Werke von Deodatus, der Dissertation und des Pantheum, können wir von Haller vernehmen ${ }^{1}$ : Die Dissertation über ein äußerst kompliziert zusammengesetztes Herzmittel beurteilt Haller sehr kritisch bis abschätzig. Dem Pantheum wirft er Weitschweifigkeit vor und das Empfehlen wertloser Medikamente wie Perlen und Korallen. - Das Exemplar, das uns zu dieser Arbeit angeregt hat, kam aus dem Zisterzienserkloster St. Urban ${ }^{7}$ in die Luzerner Kantonsbibliothek, und zwar hatte es im Kloster nicht etwa unter den mehreren tausend andern Bänden gestanden; vielmehr hatte es der Abt in seinen eigenen Gemächern aufgestellt. Ob der Gnädige Herr allein 120 Jahre alt hatte werden wollen?

\section{Anmerkungen}

1 A.von Haller, Bibliographia medicinae practicae. Bern 1776-1788, II, 362.

2 Claudius Deodatus, Pantheum... Pruntrut 1628, III, 17.

3 Ebenda, III 176.

4. Ebenda, II $182 \mathrm{ff}$.

5 Ebenda, II 192.

6 Hieronymus Guarinoni, «Grewel der Verwüstung menschlichen Geschlechts». Ingolstadt 1610.

7 J.Schürmann-Roth, Das naturwissenschaftliche und medizinische Schrifttum in der Klosterbibliothek von St. Urban. «Mitteilungen» der Naturforschenden Gesellschaft Luzern, XXV (1977) 195.

\section{Summary}

Claudius Deodatus, formed in Leyden at about 1600 , physician in ordinary to the bishopprince of Basle, has collected from all parts the advisements to remain in health and to reach 120 years of age. He exposed these advisements without criticism and without giving any own experiences ... another example of the literature about longevity.

Dr. med. Joseph Schürmann-Roth

Seefeldstraße 6

CH-6006 Luzern 